\title{
Incorporação de pó de rocha sedimentar em massas para telhas cerâmicas - Parte 1: Efeitos nas propriedades físicas e mecânicas
}

\section{(Incorporation of sedimentary powder rock in roofing tiles body - Part 1: Effect in the physical and mechanical properties)}

\author{
C.M.F.Vieira ${ }^{1}, J$. V.Emiliano ${ }^{2}$ \\ ${ }^{1}$ Laboratório de Materiais Avançados - LAMAV, Universidade Estadual do Norte Fluminense Darcy \\ Ribeiro - UENF, Av. Alberto Lamego 2000, Campos dos Goytacazes, RJ 28013-602, Brasil \\ vieira@uenf.br \\ ${ }^{2}$ Qualitech - Qualidade e Tecnologia Ltda., Av. Passos 101, sala 805, Rio de Janeiro, RJ, 20051-040, Brasil \\ qualitech@terra.com.br
}

\begin{abstract}
Resumo
Este trabalho tem por objetivo reformular uma massa típica de telhas de Campos dos Goytacazes, RJ, com adições de argilito em pó, rocha sedimentar comum em Itu, SP, e extensivamente utilizada na produção de cerâmica estrutural naquela região. Composições com argila plástica de Campos dos Goytacazes e 30, 40 e 50\% em peso de argilito em pó foram preparadas e caracterizadas. As propriedades e características das massas com argilito foram comparadas às de uma massa para telhas da região norte-fluminense. Para a determinação das propriedades físicas e mecânicas foram utilizados corpos de prova preparados por extrusão e queimados nas temperaturas entre 800 e $1050{ }^{\circ} \mathrm{C}$. As propriedades tecnológicas avaliadas foram: densidade aparente, retração linear após secagem e queima, absorção de água e resistência à flexão. Os resultados demonstram que a utilização de argilito em pó pode melhorar as propriedades das telhas cerâmicas produzidas em Campos dos Goytacazes.

Palavras-chave: argila, argilito, caulinita, telhas cerâmicas.
\end{abstract}

Abstract

This work has for objective to reformulate a typical roofing tile body from Campos dos Goytacazes with additions of shale powder from Itu, sedimentary rock extensively used for the production of structural ceramic in that region. Compositions with a plastic clay from Campos dos Goytacazes and 30, 40, and $50 \mathrm{wt} . \%$ of shale powder were prepared and characterized. The properties and characteristics of the compositions with shale were compared with a roofing tiles body from the north-fluminense region. To determine the physical and mechanical properties specimen were prepared by extrusion and fired at temperatures varying from 800 to $1050^{\circ} \mathrm{C}$. The technological properties evaluated were: bulk density, linear shrinkage, water absorption and flexural rupture strength. The results indicated that the use of shale clay powder could improve the performance of the industrial roofing tile produced in Campos dos Goytacazes.

Keywords: clay, shale clay, kaolinite, roofing tile.

\section{INTRODUÇÃO}

O pólo cerâmico do município de Campos dos Goytacazes, norte do Estado do Rio de Janeiro, produz telhas cerâmicas conformadas por prensagem cujas propriedades após queima são inferiores às dos produtos similares oriundos de outros Estados. Uma das principais deficiências das telhas produzidas em Campos dos Goytacazes é a elevada absorção de água, que pode ser atribuída, sobretudo, ao caráter caulinítico das argilas disponíveis na região, o que confere às massas cerâmicas que as contém comportamento refratário durante a queima [1-3]. Trabalhos prévios reportados na literatura enfocaram a adição de outros materiais para reduzir a porosidade após queima das massas utilizadas na produção de telhas naquela região $[4,5]$. Os resultados obtidos com granito, um dos materiais pesquisados, indicaram que a incorporação desse material em pó, com tamanho de partícula inferior a $840 \mu \mathrm{m}$, até o limite de $30 \%$ em peso, elevou a densidade aparente a seco e reduziu a absorção de água de telhas cerâmicas queimadas a $970{ }^{\circ} \mathrm{C}$ em forno industrial. Paralelamente, entretanto, verificou-se o decréscimo da resistência à flexão. A redução da resistência foi atribuída à presença de microtrincas, causadas pela transformação alotrópica do quartzo durante a etapa de resfriamento [4]. Já a incorporação de $30 \%$ em peso de argila fundente proveniente do pólo cerâmico de Santa Gertrudes, conhecida como taguá, levou a uma redução significativa da absorção de água e ao incremento da resistência à flexão de massa utilizada na produção de telhas em Campos dos Goytacazes [5]. 
O argilito, uma rocha de origem sedimentar [6], é um material comumente empregado na fabricação de telhas e blocos cerâmicos na região de Itu - SP. Uma vez que a sua composição química e mineralógica é similar às das argilas da região, este material atua como um inerte durante a secagem e apresenta, durante a queima, comportamento físico-químico similar ao da argila. Nessa combinação de materiais com características geológicas distintas, porém, propriedades físico-químicas similares, são as principais responsáveis pela boa reputação que a cerâmica estrutural produzida em Itu ainda goza.

Este trabalho tem por objetivo avaliar os efeitos de volumes variáveis de argilito em pó em uma massa preparada com o material e argila plástica caulinítica de Campos dos Goytacazes, Estado do Rio de Janeiro.

\section{MATERIAIS E MÉTODOS}

Para a realização deste trabalho foram utilizados argilito em pó, uma massa utilizada na fabricação de telhas tipo romana e portuguesa e uma argila plástica caulinítica. O argilito em pó, proveniente da região de Itu - SP é utilizado em massas para fabricação de cerâmica estrutural naquela região. Este material foi coletado na forma de pó, obtido pela trituração da rocha em moinho de martelos. A massa industrial para a produção de telhas, proveniente de indústria localizada no município de Campos dos Goytacazes - RJ, foi elaborada com a adição de $70 \%$ de uma argila plástica, denominada localmente como argila "forte", e $30 \%$ de uma argila menos plástica, com maior teor de areia, localmente denominada como argila "fraca". Tanto a massa quanto à argila foram submetidas previamente à secagem e laminação.

As quatro composições utilizadas neste trabalho são apresentadas na Tabela I. As siglas MI, AF e A representam, nessa ordem, a massa industrial, a argila forte, e o argilito em pó. Esse último foi adicionado à argila forte na razão de 30,40 e $50 \%$ em peso.

Tabela I - Composições estudadas (\% em peso). [Table I - Studied compositions (wt.\%).]

\begin{tabular}{cccc}
\hline & $\begin{array}{c}\text { Massa } \\
\text { industrial }\end{array}$ & $\begin{array}{c}\text { Argila } \\
\text { forte }\end{array}$ & $\begin{array}{c}\text { Argilito } \\
\text { de Itu }\end{array}$ \\
\hline MI & 100 & - & - \\
AF30A & - & 70 & 30 \\
AF40A & - & 60 & 40 \\
AF50A & - & 50 & 50 \\
\hline
\end{tabular}

A caracterização mineralógica das matérias-primas foi realizada por difração de raios X (DRX), em amostras em forma de pó em difratômetro Seifert URD 65, operando com radiação $\mathrm{Cu}-\mathrm{k}_{\alpha}$ e $2 \theta$ variando de $5^{\circ}$ a $40^{\circ}$. A composição química das matérias-primas foi obtida por espectrometria de fluorescência de raios X. A distribuição de tamanho de partículas foi avaliada por peneiramento e sedimentação de acordo com norma técnica NBR 7181-84 [7]. A plasticidade das composições foi obtida pelo método de Atterberg, de acordo com as normas NBR 7180-84 e NBR 6459-84 [8,9].

Corpos de prova retangulares $(108 \mathrm{~mm} \times 20 \mathrm{~mm} \times 15$ $\mathrm{mm}$ ) foram preparados por extrusão. A secagem foi em temperatura ambiente por $72 \mathrm{~h}$ seguida por secagem em estufa a $110{ }^{\circ} \mathrm{C}$, por tempo suficiente para se obter leituras constantes da massa. A queima foi realizada em forno de laboratório tipo mufla em temperaturas variando de $800^{\circ} \mathrm{C}$ a $1050{ }^{\circ} \mathrm{C}$, com intervalos de $50^{\circ} \mathrm{C}$, com taxa de aquecimento $3{ }^{\circ} \mathrm{C} / \mathrm{min}$ e $180 \mathrm{~min}$ de patamar de queima. O resfriamento foi obtido por convecção natural, desligando-se o forno. Propriedades tecnológicas relacionadas com densidade aparente, absorção de água, retração linear e tensão de ruptura à flexão ( 3 pontos) foram determinadas por meio de ensaios padronizados $[10,11]$.

\section{RESULTADOS E DISCUSSÃO}

\section{Caracterização das matérias-primas}

A Fig. 1 apresenta os difratogramas de raios $\mathrm{X}$ das matérias-primas. Tanto a massa cerâmica industrial para telhas de Campos dos Goytacazes quanto à argila forte apresentam composição mineralógica similar. São observados picos de difração associados a caulinita, mica muscovita, gibsita e quartzo. Já o argilito é composto por caulinita, mica muscovita, quartzo, hematita e microclina. A presença de microclina, um feldspato potássico, é a principal fonte de $\mathrm{K}_{2} \mathrm{O}$, que pode atuar como formador de fase líquida durante a etapa de queima, e contribuir para a redução da porosidade da cerâmica.

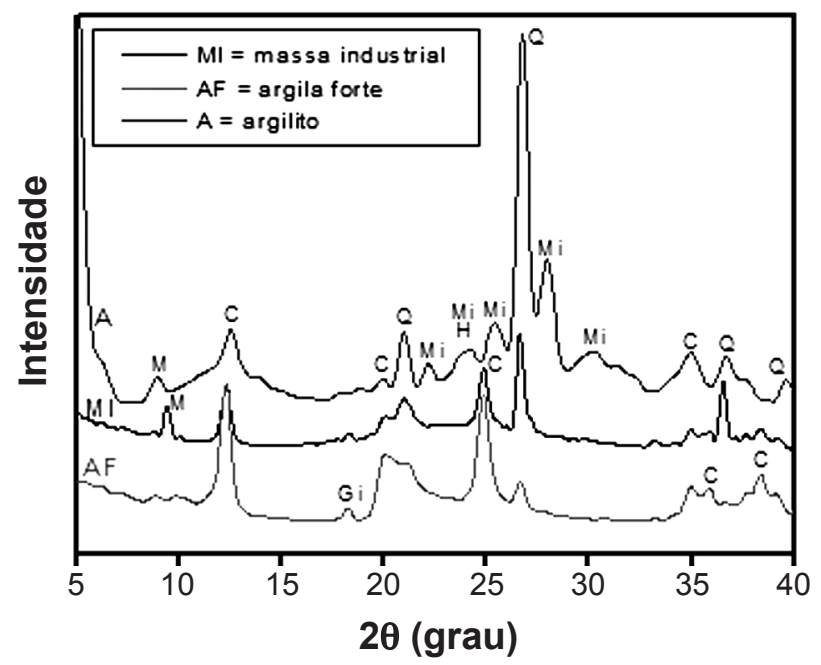

Figura 1: Difratogramas de raios $\mathrm{X}$ das matérias-primas. [Figure 1: XRD patterns of the raw materials.]

A Tabela II apresenta a composição química das matérias-primas. A massa industrial de telhas e a argila forte, ambas de Campos dos Goytacazes, apresentam baixo teor de óxidos alcalinos e alcalino-terrosos, que atuam como fundentes, e elevada perda de massa. Estes resultados estão associados à predominância da caulinita na composição mineralógica destas matérias-primas. Além 
Tabela II - Composição química das matérias-primas (\% em peso).

[Table II - Chemical composition of the raw materials (wt.\%).]

\begin{tabular}{lccccccccc}
\hline & \multicolumn{10}{c}{ Determinações } \\
\cline { 2 - 10 } Matérias-primas & $\mathrm{SiO}_{2}$ & $\mathrm{Al}_{2} \mathrm{O}_{3}$ & $\mathrm{Fe}_{2} \mathrm{O}_{3}$ & $\mathrm{TiO}_{2}$ & $\mathrm{CaO}$ & $\mathrm{MgO}$ & $\mathrm{K}_{2} \mathrm{O}$ & $\mathrm{Na}_{2} \mathrm{O}$ & $\mathrm{PF}$ \\
Massa industrial & 51,58 & 23,37 & 8,72 & 1,22 & 0,34 & 0,89 & 2,06 & 0,59 & 10,85 \\
Argila forte & 47,91 & 25,45 & 8,97 & 1,28 & 0,29 & 0,81 & 1,87 & 0,45 & 12,60 \\
Argilito & 56,02 & 17,70 & 9,04 & 1,05 & 1,11 & 4,09 & 5,77 & 0,21 & 4,80 \\
\hline
\end{tabular}

disso, a presença de hidróxido de alumínio, gibsita, também contribui para aumentar a perda de massa durante a queima e a refratariedade dessas matérias-primas. $\mathrm{O}$ argilito apresenta teor de $\mathrm{SiO}_{2}$ relativamente superior, menor teor de $\mathrm{Al}_{2} \mathrm{O}_{3}$, maior teor de óxidos fundentes e menor perda ao fogo. De acordo com sua composição mineralógica, estes resultados são atribuídos a menor quantidade de caulinita, ausência de gibsita, presença de feldspato e maior quantidade de quartzo em comparação com as matérias-primas de Campos dos Goytacazes. De acordo com a Tabela II, todas as matériasprimas apresentam elevado teor de $\mathrm{Fe}_{2} \mathrm{O}_{3}$, o que contribui para uma coloração avermelhada após queima.

A Fig. 2 apresenta a distribuição granulométrica das matérias-primas. Nesta figura as diferentes faixas de tamanho de partícula estão associadas à fração argila, silte, areia fina e areia grossa, de acordo com classificação granulométrica dos solos da International Society of Soil Science [12]. Observase que as matérias-primas de Campos dos Goytacazes apresentam tamanho de partícula predominante associada à fração "argila", $<2 \mu \mathrm{m}$. As frações silte a areia fina são relativamente próximas para todas as matérias-primas. O argilito, após moagem, é composto predominantemente por partículas associadas à areia grossa, 200 a $2000 \mu \mathrm{m}$. Entretanto, apenas 1,1\% das partículas do argilito apresenta (apresentam) tamanho superior a $840 \mu \mathrm{m}$. O tamanho médio de partícula do argilito é de $108 \mu \mathrm{m}$.

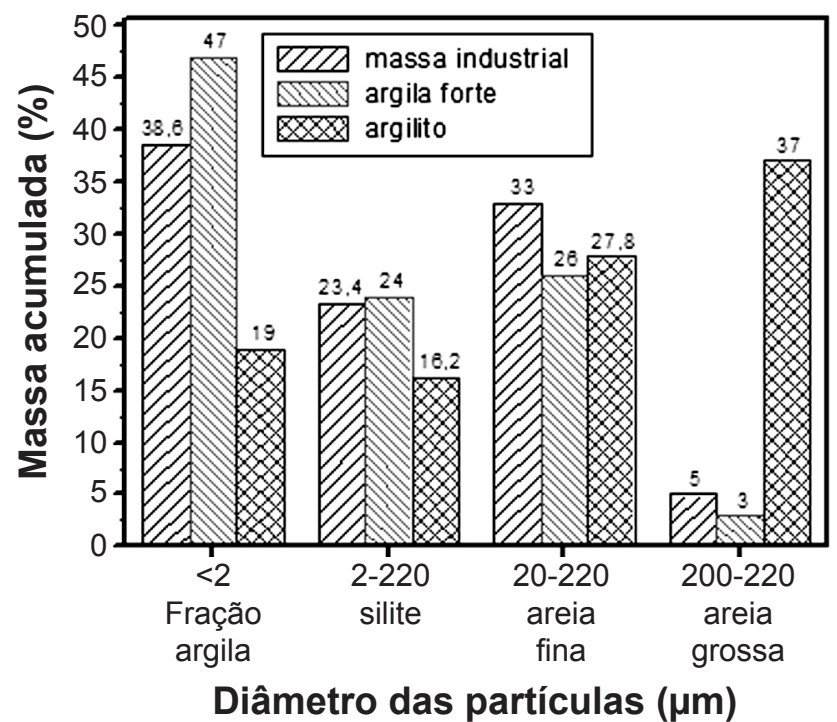

Figura 2: Distribuição de tamanho de partículas das matériasprimas (\% em peso).

[Figure 2: Particle size distribution of the raw materials (wt.\%).]

\section{Características das composições}

A Fig. 3 apresenta o diagrama de Winkler [13], no qual estão identificadas regiões adequadas de processamento de produtos de cerâmica vermelha de acordo com a granulometria do material utilizado. A região de interesse neste trabalho é a denominada $\mathbf{3}$, considerada apropriada para fabricação de telhas. Observa-se na Fig. 3 que a massa industrial de telhas de Campos dos Goytacazes MI está localizada na região 3 . Isto indica que de acordo com o seu tamanho de partícula, a massa industrial é adequada para fabricação de telhas. Esta aparente adequação da massa de Campos diz respeito apenas a trabalhabilidade por extrusão, não avaliando sua temperatura de vitrificação e, portanto, o comportamento de queima. As massas formuladas com argila forte e 40 e $50 \%$ de argilito, AF40A e AF50A, apresentam menor teor de fração argila, $<2 \mu \mathrm{m}$, e maior teor de areia, $>20 \mu \mathrm{m}$, em comparação com a massa industrial. Entretanto, todas as massas formuladas com argila forte e argilito se localizam dentro da região adequada para fabricação de telhas.

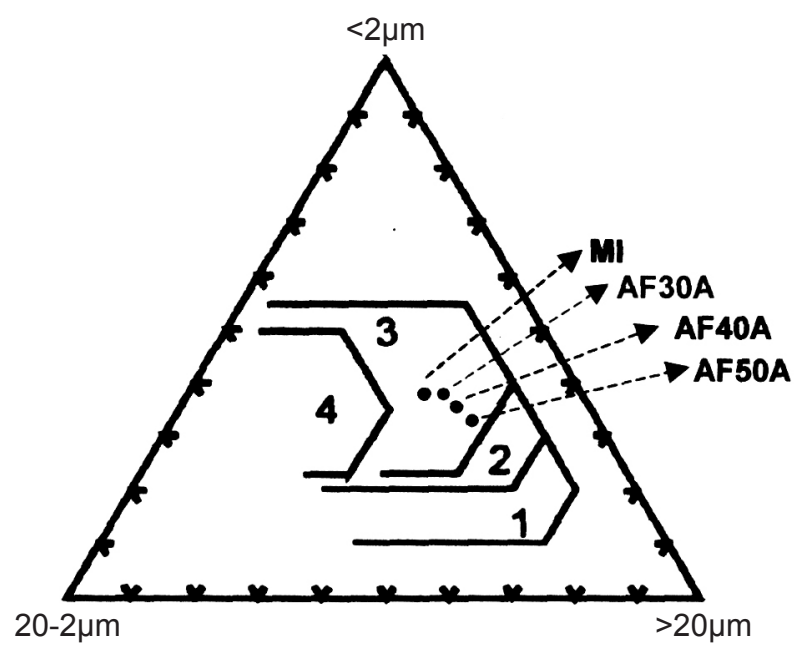

Figura 3: Diagrama de Winkler para classificação tecnológica de massas para produtos argilosos [13].

[Figure 3: Winkler diagram for the technological classification of bodies for clayey products [13].]

Através do gráfico da Fig. 4 [14], elaborado a partir dos limites de Atterberg, é possível obter um prognóstico da etapa de conformação por extrusão de matérias-primas argilosas. É possível observar que a massa cerâmica industrial utilizada para fabricação de telhas em Campos dos Goytacazes MI 


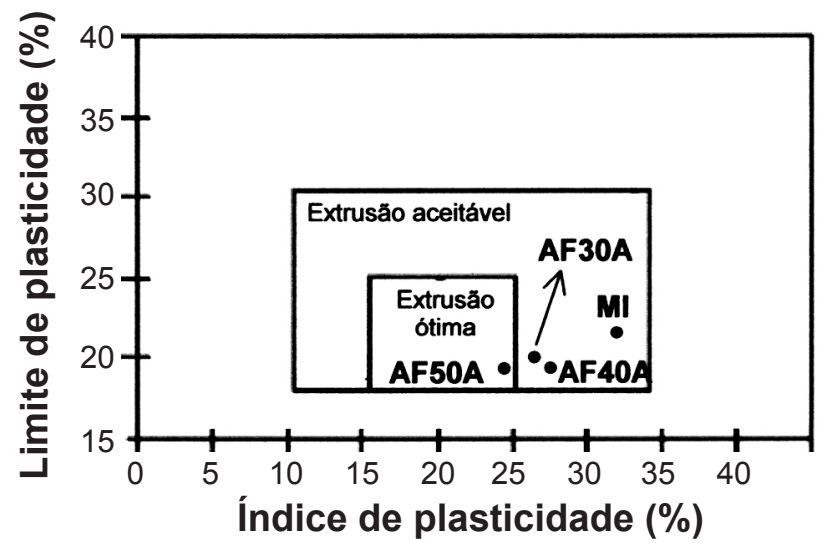

Figura 4: Prognóstico da etapa de conformação por extrusão por meio dos limites de plasticidade de Atterberg. (•) Localização das composições.

[Figure 4: Extrusion prognosis of the through plasticity Atterberg limits. $(\bullet)]$

está localizada numa região considerada aceitável para conformação por extrusão. É possível observar também que as massas formuladas com argila forte e argilito apresentam menores valores de plasticidade em comparação com a massa industrial MI. Com o incremento de argilito ocorre um deslocamento das composições em direção à região de extrusão ótima. Entretanto, só foi possível atingir esta região para a composição AF50A.

A Tabela III apresenta a composição química das composições estudadas. Observa-se que as características mais marcantes das massas cerâmicas formuladas com argila

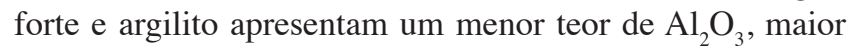
teor de óxidos fundentes alcalinos e alcalinos-terrosos e menor perda ao fogo em comparação com a massa industrial de Campos dos Goytacazes. Isto é ainda mais significativo com o incremento da incorporação de argilito.

A Tabela IV apresenta os valores de água de umidade e retração linear, densidade aparente e tensão de ruptura à flexão das peças secas das composições estudadas. Observase que as composições com argilito apresentam menor água de umidade, menor retração de secagem e maior densidade aparente a seco em comparação com a massa cerâmica industrial. Estatisticamente, a tensão de ruptura à flexão das composições praticamente não apresenta variação significativa. A redução da água de umidade das massas formuladas com argilito em comparação com a massa industrial é devida à diminuição de minerais associados à fração argila. Como consequência disto, ocorreu uma menor retração linear de secagem. Já o incremento da densidade aparente a seco com o aumento de argilito incorporado, está associado ao aumento da quantidade de areia de granulometria grossa que otimizou o empacotamento das partículas.

A Fig. 5 apresenta a densidade aparente das massas cerâmicas em função da temperatura de queima. As composições com argilito, AF30A, AF40A e AF50A apresentam densidade aparente superior à massa industrial de Campos dos Goytacazes em todas as temperaturas de queima. É possível observar também que o incremento do teor de argilito possibilitou um pequeno incremento da densidade aparente. A densidade aparente da massa industrial praticamente não apresenta variação de 800 a $1000{ }^{\circ} \mathrm{C}$. A partir daí, ocorre um pequeno incremento deste parâmetro. Para as massas com argilito, ocorre um pequeno incremento da densidade aparente a partir de $950{ }^{\circ} \mathrm{C}$. Acima de $1000{ }^{\circ} \mathrm{C}$ a densificação ocorre de forma brusca. Este comportamento é atribuído a sinterização por fluxo viscoso, denominado de vitrificação [15].

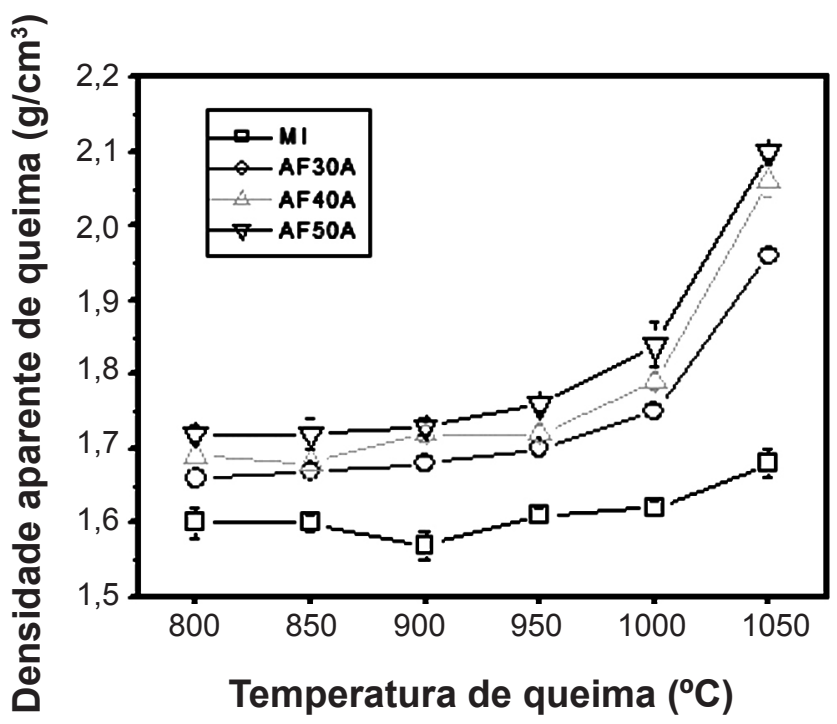

Figura 5: Densidade aparente das massas cerâmicas em função da temperatura de queima.

[Figure 5: Bulk density of the ceramic bodies as a function the firing temperature.]

Tabela III - Composição química das massas cerâmicas (\% em peso).

[Table III - Chemical composition of the ceramic bodies (wt.\%).]

\begin{tabular}{lccccccccc}
\hline Massas & \multicolumn{10}{c}{ Determinações } \\
\cline { 2 - 10 } cerâmicas & $\mathrm{SiO}_{2}$ & $\mathrm{Al}_{2} \mathrm{O}_{3}$ & $\mathrm{Fe}_{2} \mathrm{O}_{3}$ & $\mathrm{TiO}_{2}$ & $\mathrm{CaO}$ & $\mathrm{MgO}$ & $\mathrm{K}_{2} \mathrm{O}$ & $\mathrm{Na}_{2} \mathrm{O}$ & $\mathrm{PF}$ \\
MI & 51,58 & 23,37 & 8,72 & 1,22 & 0,34 & 0,89 & 2,06 & 0,59 & 10,85 \\
AF30A & 50,34 & 23,13 & 9,00 & 1,20 & 0,54 & 1,79 & 3,04 & 0,38 & 10,26 \\
AF40A & 51,15 & 22,35 & 9,00 & 1,19 & 0,62 & 2,12 & 3,43 & 0,35 & 9,48 \\
AF50A & 51,97 & 21,58 & 9,01 & 1,17 & 0,70 & 2,45 & 3,82 & 0,33 & 8,70 \\
\hline
\end{tabular}


A Fig. 6 apresenta a absorção de água das massas cerâmicas em função da temperatura de queima. Nesta figura está delimitado o percentual máximo de absorção de água a ser fixado por norma técnica nacional para fabricação de telhas cerâmicas argilosas. É possível observar que as massas com argilito apresentam menores valores de absorção de água em comparação com a massa cerâmica industrial de Campos dos Goytacazes para todas as temperaturas de queima investigadas. $\mathrm{O}$ incremento de argilito incorporado também possibilitou uma redução da absorção de água. A Fig. 6 também mostra que a massa industrial de Campos dos Goytacazes só alcança o valor de $20 \%$ de absorção de água a $1040{ }^{\circ} \mathrm{C}$. Já as composições com argilito apresentam absorção de água $<20 \%$ em todas as temperaturas investigadas. O decréscimo da absorção de água que ocorre para a massa industrial a $1000{ }^{\circ} \mathrm{C}$ e para as composições com argilito a $950^{\circ} \mathrm{C}$ é também atribuído à vitrificação.

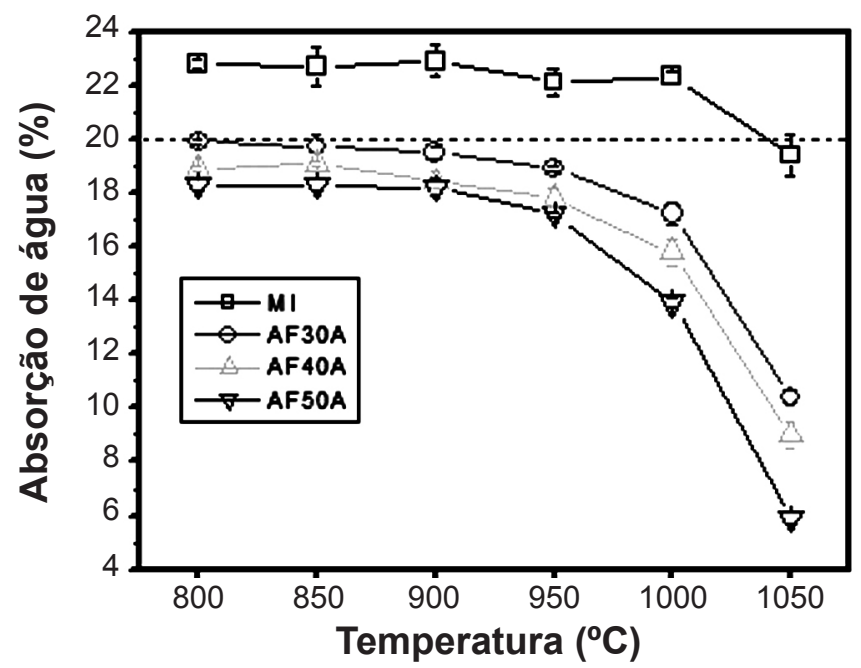

Figura 6: Absorção de água das massas cerâmicas em função da temperatura de queima.

[Figure 6: Water absorption of the ceramic bodies as a function the firing temperature.]

A Fig. 7 apresenta o comportamento da retração linear das massas cerâmicas em função da temperatura de queima. É possível observar que este parâmetro é praticamente similar para todas as composições até $950{ }^{\circ} \mathrm{C}$ e ainda apresentam

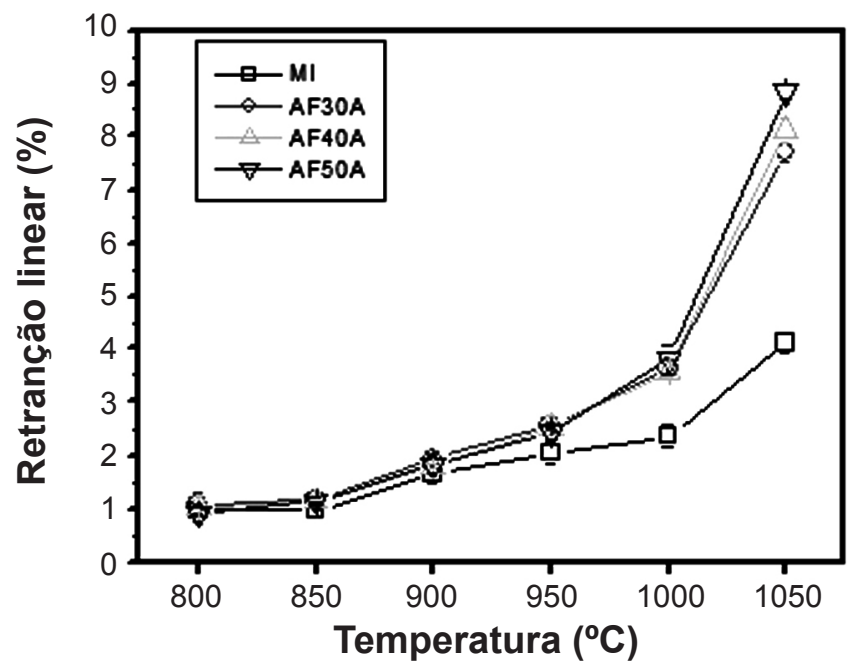

Figura 7: Retração linear das massas cerâmicas em função da temperatura de queima.

[Figure 7: Linear shrinkage of the ceramic bodies as a function the firing temperature.]

pequena variação com o incremento da temperatura. A partir daí, as composições com argilito apresentam um incremento significativo da retração linear. Este comportamento é atribuído à vitrificação que possibilita o fechamento da porosidade com aproximação das partículas devido à tensão superficial da fase líquida.

A Fig. 8 apresenta a tensão de ruptura à flexão das massas cerâmicas em função da temperatura de queima. Esta propriedade também apresenta valores mais elevados para as composições com argilito em comparação com a massa industrial. Como a resistência mecânica é fortemente dependente da porosidade do material, a redução desta contribui para este comportamento. Uma vantagem do argilito em comparação à areia, material também comumente empregado em cerâmica vermelha e que geralmente reduz a porosidade a seco das peças cerâmicas e de queima em baixas temperaturas [16], é a ausência de tensões residuais ocasionadas por coeficiente de dilatação diferenciado. A incorporação de areia pode até contribuir para a redução da absorção de água da cerâmica vermelha, mas geralmente também reduz a resistência mecânica. Com a utilização de argilito isto é minimizado devido à sua composição

Tabela IV - Parâmetros de pré-queima das massas cerâmicas.

[Table IV - Pre-firing parameters of the ceramic bodies.]

\begin{tabular}{ccccc}
\hline & \multicolumn{4}{c}{ Parâmetros } \\
\cline { 2 - 5 } Massas cerâmicas & $\begin{array}{c}\text { Água de } \\
\text { umidade } \\
(\%)\end{array}$ & $\begin{array}{c}\text { Retração linear } \\
\text { de secagem } \\
(\%)\end{array}$ & $\begin{array}{c}\text { Densidade } \\
\text { aparente a seco } \\
\left(\mathrm{g} / \mathrm{cm}^{3}\right)\end{array}$ & $\begin{array}{c}\text { Tensão de ruptura } \\
\text { à flexão a seco } \\
(\mathrm{MPa})\end{array}$ \\
\hline MI & $33,2 \pm 0,2$ & $5,2 \pm 0,1$ & $1,65 \pm 0,01$ & $3,2 \pm 0,4$ \\
AF30A & $28,9 \pm 0,1$ & $4,4 \pm 0,1$ & $1,73 \pm 0,01$ & $2,8 \pm 0,1$ \\
AF40A & $29,0 \pm 0,1$ & $4,7 \pm 0,2$ & $1,75 \pm 0,01$ & $2,9 \pm 0,1$ \\
AF50A & $26,9 \pm 0,3$ & $4,5 \pm 0,1$ & $1,78 \pm 0,02$ & $3,0 \pm 0,2$ \\
\hline
\end{tabular}




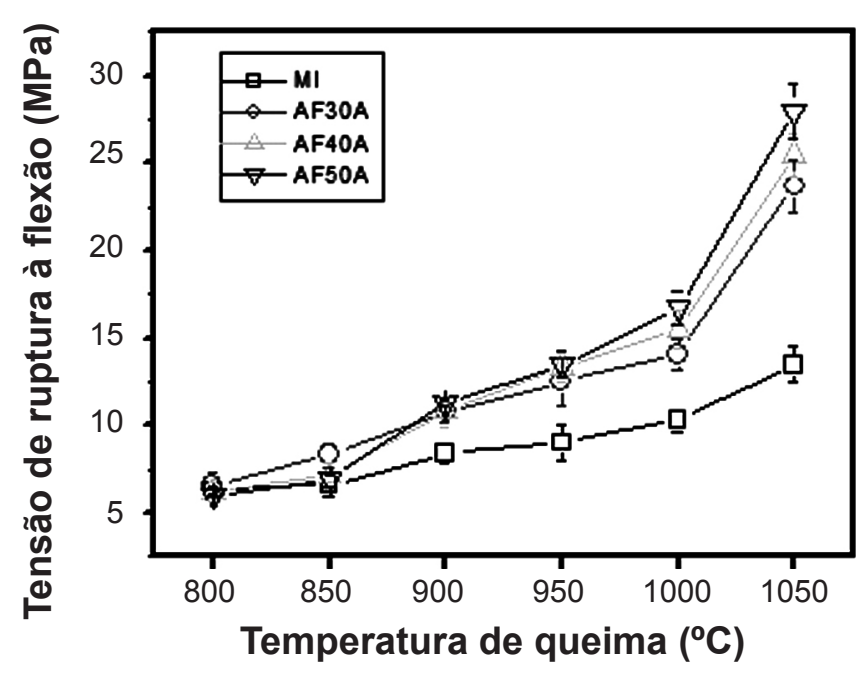

Figura 8: Tensão de ruptura à flexão das massas cerâmicas em função da temperatura de queima.

[Figure 8: Flexural rupture strength of the ceramic bodies as a function the firing temperature.]

mineralógica similar às argilas.

Como considerações finais, em relação às propriedades tecnológicas de queima avaliadas pode-se afirmar que as composições com argilito possibilitaram uma redução da absorção de água e incremento da resistência mecânica e da densidade aparente em comparação com uma típica massa industrial de telhas de Campos dos Goytacazes. Este comportamento é devido a três fatores tais como maior densidade aparente a seco, menor perda de massa durante a queima e maior formação de fase líquida. Este último fator é mais significativo para temperaturas acima de $950^{\circ} \mathrm{C}$.

\section{CONCLUSÕES}

Observou-se que a incorporação de argilito a uma argila plástica caulinítica de Campos dos Goytacazes melhora significativamente a trabalhabilidade e as propriedades tecnológicas de queima, por meio da redução da porosidade. Como consequiência, ocorre uma redução da absorção de água e incremento da resistência mecânica em comparação com a massa industrial de telhas de Campos dos Goytacazes. Em baixas temperaturas, a redução da porosidade é mais fortemente influenciada pelo maior valor da densidade aparente a seco e menor perda de massa durante a queima das composições com argilito. Em temperaturas acima de $950{ }^{\circ} \mathrm{C}$, a formação de fase líquida possibilitou uma maior redução da porosidade, que é mais significativa com o incremento da quantidade de argilito incorporado. Apesar da distância significativa das jazidas de argilito de Itu para o município de Campos dos Goytacazes, 900 km, a incorporação de cerca de $30 \%$ de argilito a argilas de campos dos Goytacazes para fabricação de telhas pode ser economicamente viável.

\section{AGRADECIMENTOS}

Os autores agradecem a FAPERJ, Proc. E-26/111.166/2011 e ao CNPq, Proc. 301778/2011-6.

\section{REFERÊNCIAS}

[1] C. M. F. Vieira, T. M. Soares, S. N. Monteiro, Cerâmica 49, 312 (2003) 245.

[2] S. N. Monteiro, R. Sánchez, C. M. F. Vieira, Silicates Industriels 69, 11-12 (2004) 103-109.

[3] S. N. Monteiro, C. M. F. Vieira, Appl. Clay Sci. 27 (2004) 229.

[4] C. M. F. Vieira, T. M. soares, S. N. Monteiro, Cerâmica Industrial 9, 1 (2004) 28.

[5] C. M. F. Vieira, H. F. Sales, S. N. Monteiro, Cerâmica 50, 315 (2004) 239.

[6] V. Leinz, S. E. do Amaral, Geologia Geral, Ed. Nacional, São Paulo, SP (1998) p. 46-47.

[7] Associação Brasileira de Normas Técnicas - ABNT, Determinação da Análise Granulométrica dos solos, NBR - 7181-84, 1984.

[8] Associação Brasileira de Normas Técnicas - ABNT, Determinação do Limite de Plasticidade, NBR - 7180, Rio de Janeiro, RJ (1984).

[9] Associação Brasileira de Normas Técnicas - ABNT, Determinação do Limite de Liquidez, NBR - 6459, Rio de Janeiro, RJ (1984).

[10] American Society for Testing and Materials - ASTM, Water Absorption, Bulk Density, Apparent Porosity, and Apparent Specific Gravity of Fired Whiteware Products, C 373-72 (1972).

[11] American Society for Testing and Materials - ASTM, Flexural Properties of Ceramic Whiteware Materials, C 674-77 (1977).

[12] P. S. Santos, Ciência e Tecnologia das Argilas, vol. 1, Ed. Edgard Blücher Ltda., São Paulo (1989) p. 5.

[13] H. G. F. Winkler, Ber. Dtsch. Keram. Ges. 31 (1954) 337.

[14] M. Marsigli, M. Dondi, L'Industria dei Laterizi 46 (1997) 214.

[15] W. D. Kingery, H. K. Bowen, D. R. Uhlmann, Introduction to Ceramics, Ed. John Wiley \& Sons, New York, EUA (1995) p. 495.

[16] H. F. Sales, C. M. F. Vieira, J. Alexandre, M. P. Soares Jr., S. N. Monteiro, Anais do XV CBECIMAT, Natal, RN (2002).

(Rec. 23/05/2012, Ac. 28/12/2012) 